\title{
A novel splicing site mutation of the GPR143 gene in a Chinese $\mathrm{X}$-linked ocular albinism pedigree
}

\author{
C.Y. Cai ${ }^{1 *}$, H. Zhu ${ }^{2 *}$, W. Shi ${ }^{1 *}$, L. Su ${ }^{3 *}$, O. Shi ${ }^{4}$, C.Q. Cai ${ }^{5}$, C. Ling ${ }^{1}$ and \\ W.D. $\mathbf{L i}^{1}$ \\ ${ }^{1}$ Research Center of Basic Medical Sciences, Tianjin Medical University, \\ Tianjin, China \\ ${ }^{2}$ College of Public Health, Tianjin Medical University, Tianjin, China \\ ${ }^{3}$ Eye Center, Tianjin Medical University, Tianjin, China \\ ${ }^{4}$ School of Basic Medical Sciences, Tianjin Medical University, Tianjin, China \\ ${ }^{5}$ Department of Surgery, Tianjin Children's Hospital, Tianjin, China \\ *These authors contributed equally to this study. \\ Correspondence author: W.D. Li \\ E-mail: liweidong98@tijmu.edu.cn
}

Genet. Mol. Res. 12 (4): 5673-5679 (2013)

Received March 26, 2013

Accepted September 16, 2013

Published November 18, 2013

DOI http://dx.doi.org/10.4238/2013.November.18.16

\begin{abstract}
Ocular albinism is an X-linked inherited disease characterized by hypopigmentation of the iris and nystagmus. To identify a new diseasecausing mutation of ocular albinism, we collected a Han Chinese pedigree with 7 male congenital nystagmus patients over 3 generations. Slit-lamp photography and optical coherence tomography were performed for the proband. Genomic DNA was extracted from a whole blood sample from the proband using the high-salt method. Polymerase chain reaction (PCR) sequencing was carried out for GPR143 and FRMD7 genes. The threedimensional structures of the wild-type and mutant GPR143 proteins were determined using SWISS-MODEL. The transmission of the disease in the pedigree clearly followed an X-linked pattern. The proband had significant iris and fundus hypopigmentation. Optical coherence tomography showed severe foveal hypoplasias in both eyes of the proband. A novel splicing site $(\mathrm{G} / \mathrm{C})$ mutation was found on the boundary of the 6th intron and the 7th
\end{abstract}


exon of the GPR143 gene, resulting in a 9-amino-acid deletion (codons 257-265) in the 6th transmembrane domain of the GPR143 protein. In conclusion, a novel splicing site mutation of the GPR143 gene was found in a Han Chinese congenital ocular albinism pedigree.

Key words: Ocular albinism; GPR143; Congenital nystagmus; Pedigree; Han Chinese

\section{INTRODUCTION}

X-linked ocular albinism, also called Nettleship-Falls ocular albinism (ocular albinism type 1, OA1), is an X-linked inherited disease characterized by hypopigmentation of the iris and nystagmus. Unlike other nystagmus diseases, OA1 patients also have an albinotic fundus and macular hypoplasia in addition to iris hypopigmentation. X-linked congenital nystagmus 6 (NYS6) is a similar disease, but without albinism. Genes or loci for several X-linked congenital nystagmus diseases have been identified, including the FERM domain containing 7 gene (FRMD7) for NYS1 (Tarpey et al., 2006), and both NYS6 and OA1 are caused by mutations in the G protein-coupled receptor 143 gene (GPR143) (Bassi et al., 1995).

A patient with "nystagmus" sought genetic consultation, since multiple male members in his family had similar symptoms. A review of his family history showed that the disease transmission clearly followed an X-linked pattern. We therefore sequenced both the FRMD7 and GPR143 genes in the proband to identify the disease-causing mutation.

\section{MATERIAL AND METHODS}

\section{Family history and ophthalmological exams}

The proband was a 34 year-old male; his nystagmus was present since birth. There were 7 male congenital nystagmus patients within 3 generations in his family (Figure 1). He gave informed consent prior to this study, and the protocol was approved by the Committee on Studies Involving Human Beings at Tianjin Medical University. Other family members, including all 6 other patients, refused to take part in this study. Family histories were provided by the proband.



Figure 1. Chinese pedigree with ocular albinism. Arrow indicates the proband.

The proband underwent ophthalmological examination, including visual acuity assessment, slit-lamp biomicroscopy, and intraocular eye pressure measurement. Anterior and posterior segments of the eyes were documented by slit-lamp and fundus photography. 


\section{DNA extraction and sequencing and protein structural analysis}

A whole blood sample was collected from the proband, and genomic DNA was extracted from the sample using the standard high-salt method. All exons and splicing sites of FRMD7 and GPR143 were amplified by PCR and sequenced with both forward and reverse primers. PCR primers were designed using the Primer3 software (http://frodo.wi.mit.edu/primer3/) and are shown in Table 1. The three-dimensional structures of the wild-type and mutant GPR143 protein were predicted using the SWISS-MODEL (http://swissmodel.expasy.org/).

\begin{tabular}{|c|c|c|}
\hline Exon & Left primer & Right primer \\
\hline Exon 1 & gcgttageccagtgctctc & gcgetgatcagattccaac \\
\hline Exon 2 & tttccaaagcaagaagtcagc & ctgcgatttgaggagcataa \\
\hline Exon 3 & gtctaccetgecgtctcaag & aacgetcagtgccatctctt \\
\hline Exon 4 & getgttgtgettgtccecta & tgagacaacggectaacctc \\
\hline Exon 5 & gccaaaactttgcttttgaga & cgtgtacccagagagettcc \\
\hline Exon 6 & ctgettccattgecttctct & cettccactggcaataaaa \\
\hline Exon 7 & cetgetgccattttctttct & agcctgggtgacagagtgag \\
\hline Exon 8 & tgccatgtgtctttctgtcc & cccgaagtctacetgetgtg \\
\hline Exon 9 & aacctgctaggacacagacaca & atccaagtcaggctgagagc \\
\hline
\end{tabular}

\section{RESULTS}

\section{Clinical evaluations}

The proband had poor visual acuity and nystagmus. Both eyes showed mild myopia and astigmatism, and the best corrected visual acuity was 0.3 for the right eye and 0.5 for the left eye. Results of the flash visual evoked potential and visual field tests were normal. The proband had normal skin and hair. He had mild peripheral iris hypopigmentation and mild atrophy at the inferior parts of the iris in both eyes (Figure 2A), hypopigmentation in the posterior of the fundus in both eyes (Figure 2B), and medullated nerve fibers around the superior and nasal edge of the disc of the left eye. Optical coherence tomography showed severe foveal hypoplasias in both eyes (Figure 2C). No head nodding or other neurological symptoms were observed in the proband.

As recalled by the proband, all other patients in the pedigree had similar nystagmus and iris hypopigmentation.

\section{A GPR143 splicing site mutation}

A splicing site $(\mathrm{G} / \mathrm{C})$ mutation $(24422 \mathrm{G}>\mathrm{C})$ was found on the boundary of the 6th intron and the 7th exon of the GRP143 gene (Figure 3A), resulting in a 9-amino-acid deletion (W L S N I I N E S, codons 257-265) in the 6th transmembrane domain of the GPR143 protein (Figure 3B). No mutation was found in the FRMD7 (NYS1) gene.

\section{Three-dimensional structure prediction of the mutant GPR143}

Protein three-dimensional construction was performed for both wild-type and mu- 
tants. The 9-amino-acid deletion was located in the alpha helix of the 6th transmembrane domain (Figure 3C).

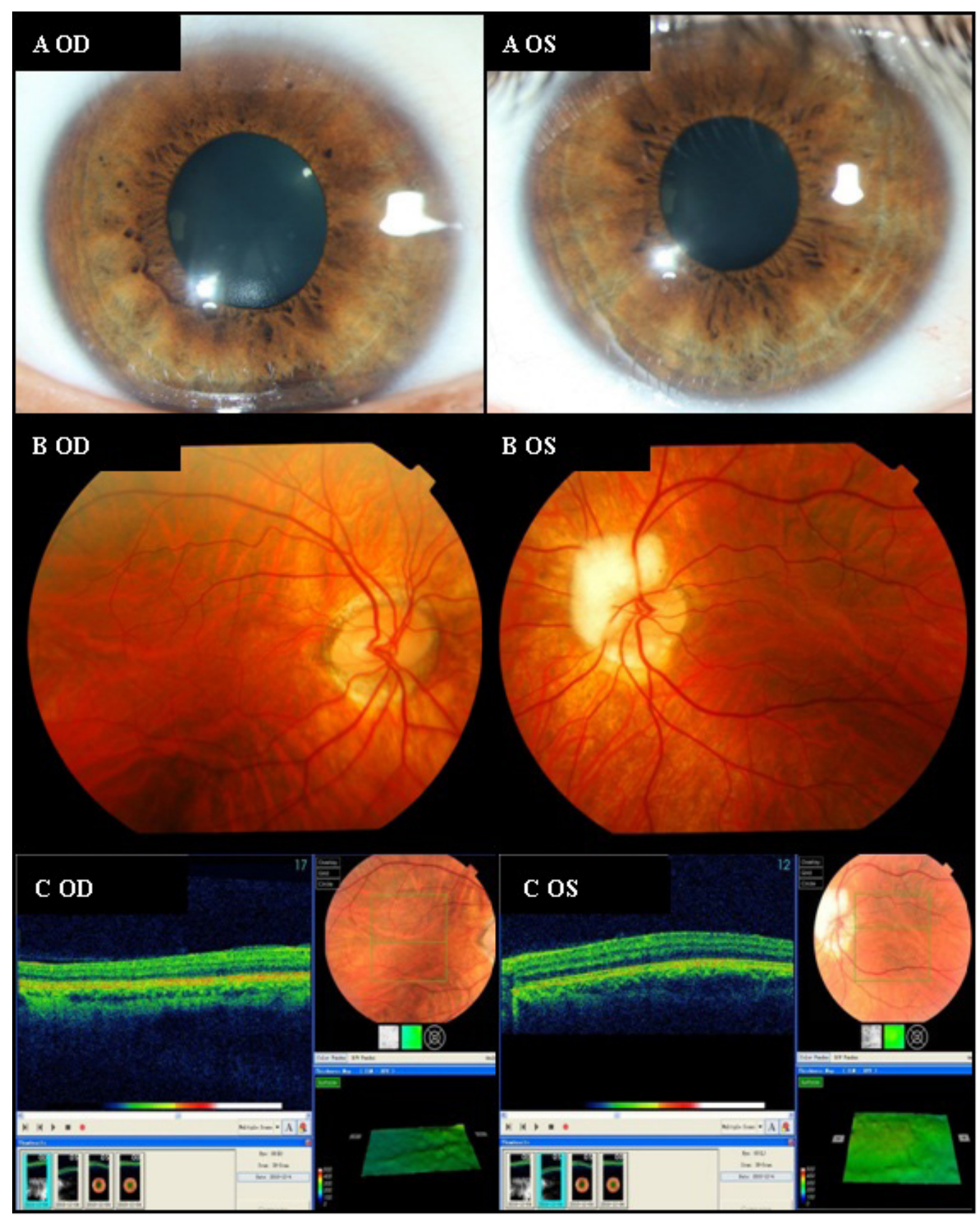

Figure 2. Clinical evaluations of the proband. A. Slit lamp exam showed iris hypopigmentation. B. Albinotic fundus showed by fundus photography. C. Optical coherence tomography showed severe foveal hypoplasias. 


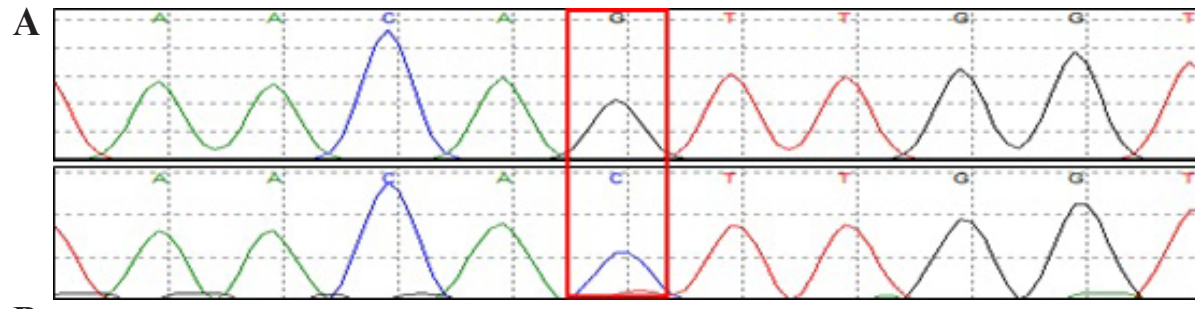

B normal del normal del

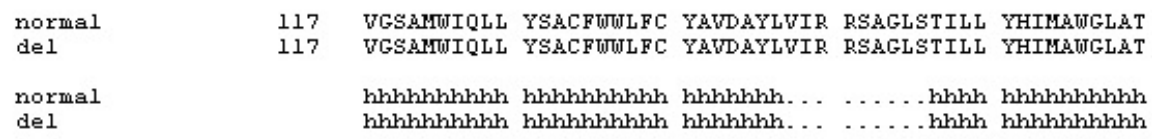

\begin{tabular}{|c|c|c|c|c|c|c|}
\hline $\begin{array}{l}\text { normal } \\
\text { del }\end{array}$ & $\begin{array}{l}167 \\
167\end{array}$ & $\begin{array}{l}\text { LLCVEGAMML } \\
\text { LLCVEGAMML }\end{array}$ & $\begin{array}{l}\text { YYPSUSRCER } \\
\text { YYPSVSRCER }\end{array}$ & $\begin{array}{l}\text { GLDHAIPHYV } \\
\text { GLDHAIPHYV }\end{array}$ & $\begin{array}{l}\text { TMYLPLLLVL } \\
\text { TMYLPLLLVL }\end{array}$ & $\begin{array}{l}\text { VANPILFOKT } \\
\text { VANPILFOKT }\end{array}$ \\
\hline $\begin{array}{l}\text { normal } \\
\text { del }\end{array}$ & & $\begin{array}{l}\text { hhhhhhhhhhh. } \\
\text { hhhhhhhhh. }\end{array}$ & $\ldots \ldots \ldots h$ & $\begin{array}{l}\text { hhahhhhh. } \\
\text { h.......... }\end{array}$ & $\begin{array}{l}\text {. hhhhhhhhhh } \\
\text {. hhhhhhhh }\end{array}$ & $\begin{array}{l}\text { hhh } \ldots \ldots h h \\
h \ldots \ldots \ldots\end{array}$ \\
\hline norr & 217 & VTAVASLLKG & RQGIYT ENER & RMGAVIKIRF & FKIMLVLIIC & WLSNIINESL \\
\hline del & 217 & VTAVASLLKG & RQGIYT ENER & RMGAVIKIRF & FKIMLVLIIC & LLFYL EMQTD \\
\hline $\begin{array}{l}\text { normal } \\
\text { del }\end{array}$ & & $\begin{array}{l}\text { hhhh........ } \\
\text { hhhhh.... }\end{array}$ & & $\begin{array}{l}\ldots \ldots \ldots h \mathrm{~h} \\
\ldots \ldots \ldots h h h\end{array}$ & $\begin{array}{l}\text { hhhhhhhhhhhh } \\
\text { hhhhhhhhhh }\end{array}$ & $\begin{array}{l}\text { hahhhhhhhrt } \\
\text { hhhhhhh. }\end{array}$ \\
\hline
\end{tabular}

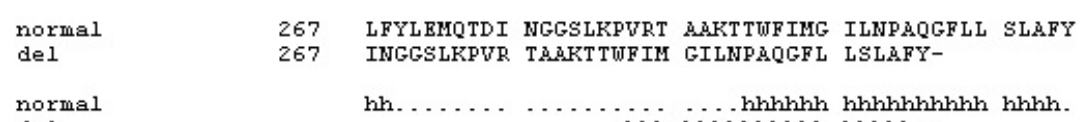

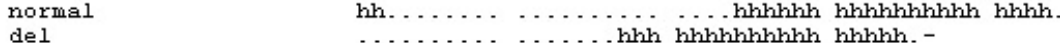

C

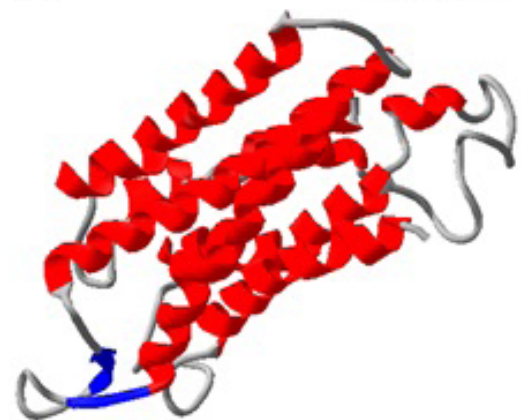

Wild type

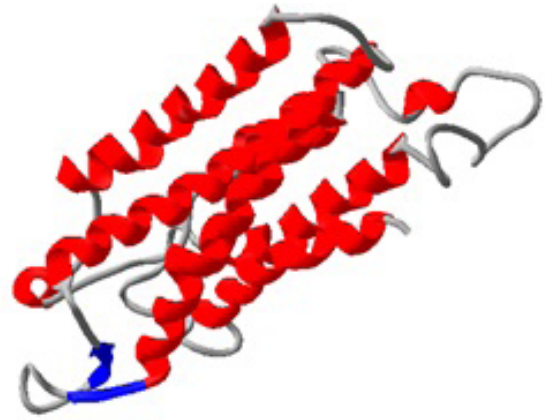

Mutant

Figure 3. GPR143 gene sequencing and predicted three-dimensional structure of the mutant GPR143 protein. A. PCR sequencing showed a $\mathrm{G}$ to $\mathrm{C}$ mutation $(24422 \mathrm{G}>\mathrm{C}$; red rectangle) at the 6 th intron- 7 th exon boundary. B. The mutation results in a 9-amino-acid deletion (red rectangle) located in the 6th transmembrane domain. C. Threedimensional structure prediction by SWISS-MODEL. 


\section{DISCUSSION}

X-linked ocular albinism type 1 , or Nettle-Falls type ocular albinism (OA1), is the most common inherited ocular albinism, with a prevalence of 1 in 60,000 live births in the Danish population (Rosenberg and Schwartz, 1998). Unlike other kinds of ocular albinism, OA1 patients usually do not have abnormal skin pigmentation.

A mutation of the GPR143 gene was first identified in an OA1 pedigree by Bassi et al. (1995). Since then, approximately 90 GPR143 mutations have been found in OA1, which include approximately $60 \%$ missense mutations, and nonsense, frameshift, and splicing site mutations resulting in amino acid deletions (Rosenberg and Schwartz, 1998; Schnur et al., 1998; Oetting, 2002; Peng et al., 2009). Interestingly, the X-linked disease NYS6, which is associated with nystagmus, reduced vision, and amblyopia, but not ocular albinism, was also shown to be caused by GPR143 mutations (Liu et al., 2007; Zhou et al., 2008; Peng et al., 2009). Several studies have found GPR143 mutations in the Chinese population, including a Chinese pedigree with iris hyperpigmentation and nystagmus (Xiao and Zhang, 2009).

GPR143 is highly expressed in the retinal pigment epithelium and melanocytes. Unlike other G-protein-coupled receptors, GPR143 is located in the melanosomes, Golgi apparatus, and lysosome membrane rather than in the plasma membrane (Schiaffino et al., 1999). Giordano et al. (2009) found that short interfering RNA GPR143-depleted cells had reduced melanosome numbers and were of abnormal size and composition. d'Addio et al. (2000) expressed 19 GPR 143 mutations in COS-7 cells, and most caused intracellular transport problems. GPR143-knockout mice showed hypopigmentation of the ocular fundus and giant melanosomes in the retinal pigment epithelium (Incerti et al., 2000).

Lopez et al. (2008) found that L-dopa was an endogenous ligand of GPR143. Dopamine competes with L-dopa for GPR143 binding, which explains nystagmus as the main feature in patients with GPR143 mutations. However, NYS6 patients do not usually have ocular albinism, and some of even have hyperpigmentation of the iris (Xiao and Zhang, 2009). To date, the specific mutation causing abnormal pigmentation remains unknown.

In our study, the 9-amino-acid deletion in the 6th transmembrane domain (codons 257-265) might change the GPR143 protein structure significantly (Figure 3C). The proband demonstrated typical iris hypopigmentation and nystagmus. However, hypopigmentation, the key difference between OA1 and NYS6, is not associated with the severity of GPR143 mutations. In many individuals with GPR143 frameshift mutations, nystagmus is found without hypopigmentation even if the GPR143 protein is almost 75\% truncated (Zhou et al., 2008; Peng et al., 2009). Therefore, more functional analyses are needed to decipher the phenotypegenotype correlation in ocular albinism and nystagmus patients.

In summary, we identified a novel splicing site mutation of the GPR143 gene in a Han Chinese congenital ocular albinism pedigree. The mutation causes a 9-amino-acid deletion in exon 7 . Three-dimensional structure prediction indicated a significant change in the 6th transmembrane domain of the GPR143 protein.

\section{ACKNOWLEDGMENTS}

Research supported partilly by a grant (\#81070576) from the National Natural Science Foundation of China (NSFC), a grant (\#12JCZDJC24700) from the Tianjin Municipal 
Science and Technology Commission to W-D. Li, the Natural Science Foundation of Tianjin Medical University (\#2010ky09) to W.T. Shi, and the Key Project of Tianjin Health Care Professionals (\#12KG116) to C.Q. Cai.

\section{REFERENCES}

Bassi MT, Schiaffino MV, Renieri A, De NF, et al. (1995). Cloning of the gene for ocular albinism type 1 from the distal short arm of the X chromosome. Nat. Genet. 10: 13-19.

d'Addio M, Pizzigoni A, Bassi MT, Baschirotto C, et al. (2000). Defective intracellular transport and processing of OA1 is a major cause of ocular albinism type 1. Hum. Mol. Genet. 9: 3011-3018.

Giordano F, Bonetti C, Surace EM, Marigo V, et al. (2009). The ocular albinism type 1 (OA1) G-protein-coupled receptor functions with MART-1 at early stages of melanogenesis to control melanosome identity and composition. Hum. Mol. Genet. 18: 4530-4545.

Incerti B, Cortese K, Pizzigoni A, Surace EM, et al. (2000). Oa1 knock-out: new insights on the pathogenesis of ocular albinism type 1. Hum. Mol. Genet. 9: 2781-2788.

Liu JY, Ren X, Yang X, Guo T, et al. (2007). Identification of a novel GPR143 mutation in a large Chinese family with congenital nystagmus as the most prominent and consistent manifestation. J. Hum. Genet. 52: 565-570.

Lopez VM, Decatur CL, Stamer WD, Lynch RM, et al. (2008). L-DOPA is an endogenous ligand for OA1. PLoS Biol. 6: e236.

Oetting WS (2002). New insights into ocular albinism type 1 (OA1): Mutations and polymorphisms of the OA1 gene. Hum. Mutat. 19: 85-92.

Peng Y, Meng Y, Wang Z, Qin M, et al. (2009). A novel GPR143 duplication mutation in a Chinese family with X-linked congenital nystagmus. Mol. Vis. 15: 810-814.

Rosenberg T and Schwartz M (1998). X-linked ocular albinism: prevalence and mutations - a national study. Eur. J. Hum. Genet. 6: 570-577.

Schiaffino MV, d'Addio M, Alloni A, Baschirotto C, et al. (1999). Ocular albinism: evidence for a defect in an intracellular signal transduction system. Nat. Genet. 23: 108-112.

Schnur RE, Gao M, Wick PA, Keller M, et al. (1998). OA1 mutations and deletions in X-linked ocular albinism. Am. J. Hum. Genet. 62: 800-809.

Tarpey P, Thomas S, Sarvananthan N, Mallya U, et al. (2006). Mutations in FRMD7, a newly identified member of the FERM family, cause X-linked idiopathic congenital nystagmus. Nat. Genet. 38: 1242-1244.

Xiao X and Zhang Q (2009). Iris hyperpigmentation in a Chinese family with ocular albinism and the GPR143 mutation. Am. J. Med. Genet. A 149A: 1786-1788.

Zhou P, Wang Z, Zhang J, Hu L, et al. (2008). Identification of a novel GPR143 deletion in a Chinese family with X-linked congenital nystagmus. Mol. Vis. 14: 1015-1019. 